\title{
Erişkinde İleal Polibe Sekonder İleoileal İnvajinasyon Adult Ileoileal Intussusception Secondary to a Ileal Polip
}

Bartu Badak

Eskişehir Osmangazi Üniversitesi Tıp Fakültesi Genel Cerrahi Anabilim Dalı, Eskişehir, Türkiye

Öz: Erişkinlerde safra yollarının spontan perforasyonu çok nadir ortaya çıkan bir durumdur. Bu vaka sunumunda, safra yollarından taş çıkarılması ve kronik pankreatite bağlı gelişen benign striktüre nedeniyle peşpeşe stent takılma öyküsü olan ve safra peritoniti nedeniyle cerrahiye alınan 75 yaşında bir hasta takdim ettik. Safra yollarına takılan stentin çıkarılmasını takiben gelişen ilk koledok perforasyonu vakasıdır. Bu hastada, ERCP'de striktürün devam ettiği görüldükten sonra başka endoskopik prosedürler planlamak yerine elektif cerrahi enterobilier diversiyonun uygulanması gerektiğini düşünmekteyiz.

Anahtar Kelimeler: Koledok, perforasyon, stent, pankreatit,enterobilier diversiyon

Badak B. (2017). Erişkinde İleal Polibe Sekonder İleoileal İnvajinasyon, Osmangazi Tip Dergisi 39(2):56-59. DOI:10.20515/otd.21120

\begin{abstract}
Spontaneous bile duct perforation is a very rare entity in adults. In this report, we present a 75 -yearold patient with a history of extraction of bile duct stones and serial stent placement because of chronic pancreatitis related-benign stricture who underwent surgery due to biliary peritonitis. This is the first case of common bile duct perforation following removal of biliary stent. We thought that an elective surgical enterobiliary diversion should have been performed in this patient after detecting the persistence of the stricture on ERCP instead of planning future endoscopic procedures.
\end{abstract}

Keywords: Choledochus, perforation, stent, stricture, pancreatitis, enterobiliary diversion 


\section{Giriş}

İnvajinasyon gastrointestinal sistemde traktın bir bölümünün, bu bölümü takip eden distal segmentle iç içe geçmesi olarak tanımlanır(1). Çocuklarda daha sık görülen invajinasyonlar bu yaş grubunda intestinal obstrüksiyonların temel sebebiyken erişkinlerde $\% 5$ oranından daha nadir görülür. (2) Erişkin invajinasyonları ise bu yaş grubundaki ileusların \% 5'inin sebebi olarak görülür. (2) Çocuklarda görülen invajinasyonların \%90'1 idiopatikken erişkinlerde oluşan invajinasyonların sıklıkla bir etyolojik nedeni bulunabilmektedir. (3) Enterik, kolonik veya ileokolik şekilde gözelenebilen invajinasyonlar nonspesifik semptomların sıklığ 1 nedenli genellikle operasyonlaparatomi esnasinda tanı alırlar. (4) $\mathrm{Bu}$ sunumda biz acil servise karın ağrısı nedeniyle başvuran ve yapılan tetkikler sonucu invajinasyon?, meckel divertikülü? saptanan hastanın operasyon sürecini ve bulgularını sunduk.

\section{Olgu Sunumu}

Acil servise karın ağrısı nedeniyle başvuran 74 yaşında bayan hasta yapılan tetkikler sonucu batında özellikle sağ alt kadranda hassasiyet saptanmasi üzerine genel cerrahi kliniğine yatırıldı. Batın muayenesinde defans ve rebound saptanmayan hastaya etyolojik araştırma için abdomen bilgisayarlı tomografi çekildi. Sonuç intestinal segmentlerde invajinasyon?, meckel divertikülü? gelmesi üzerine elektif operasyona hazırlanan hastanın tam kan sayımı ve biyokimyasal parametrelerinde herhangi bir bozukluk saptanmadi. Ek dahili hastalık olarak sadece hipertansiyon hikayesi bulunan hasta preoperatif hazırlıklar tamamlandıktan sonra operasyona alındı. Laparotomi esnasinda distal ileal segmentlerde invajinasyon hali saptanan hastaya yapilan enterotomi esnasinda invajinasyona sebep olarak lümen içi yaklaşık $3 \mathrm{~cm}$ boyutlarında polip gözlemlendi. İleal yaklaşı $10 \mathrm{~cm}$ 'lik segmenter rezeksiyon ve ucuca anastomoz yapilan hastaya postoperatif 2. günde oral alım başlanarak hasta 5. günde şifa ile taburcu edildi. Hatanın spesmen patoloji sonucu 'inflamatuar fibroid polip' olarak raporland1.
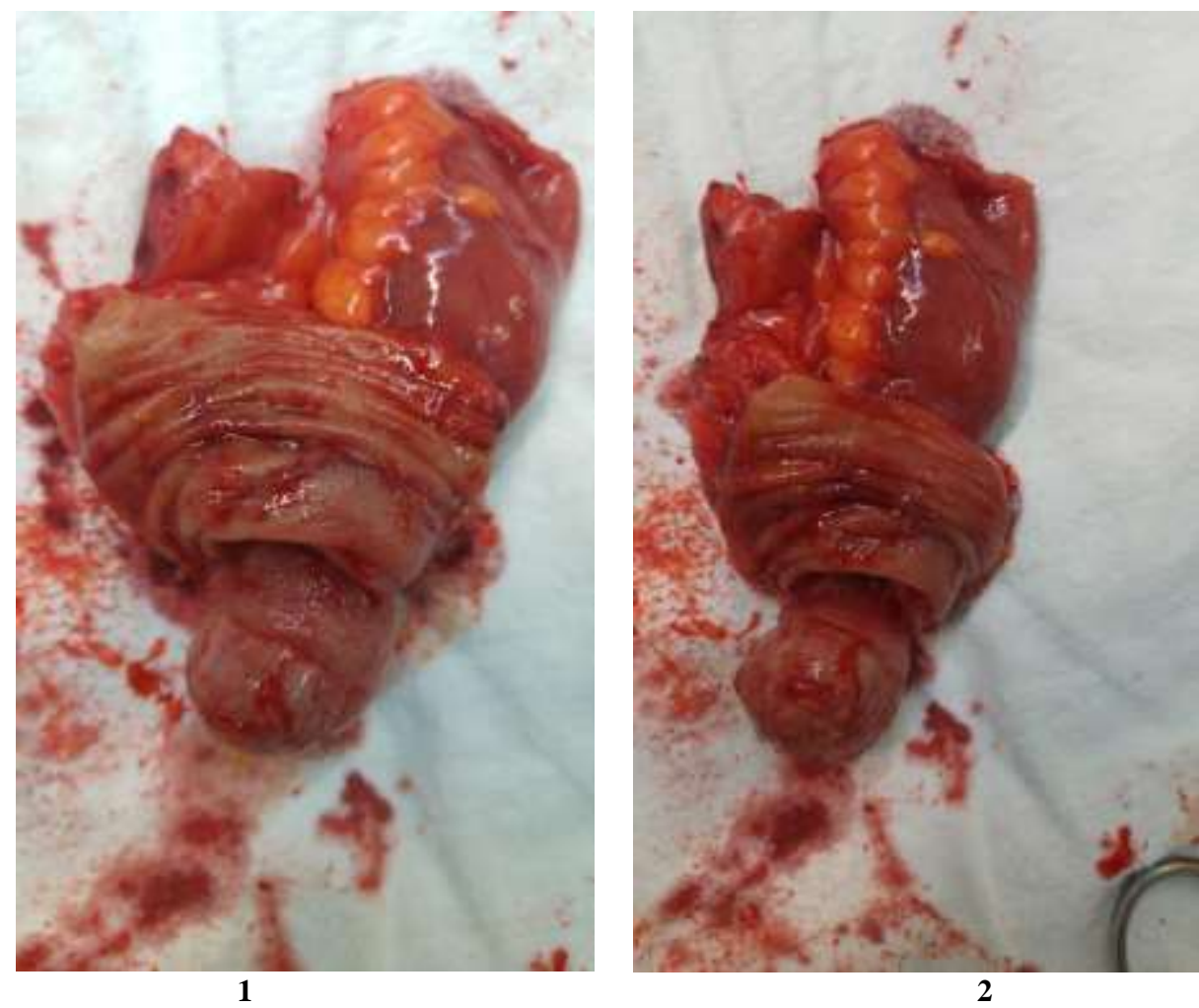

Resim 1-2. Invajinasyona sebep olan inflamatuar polip 


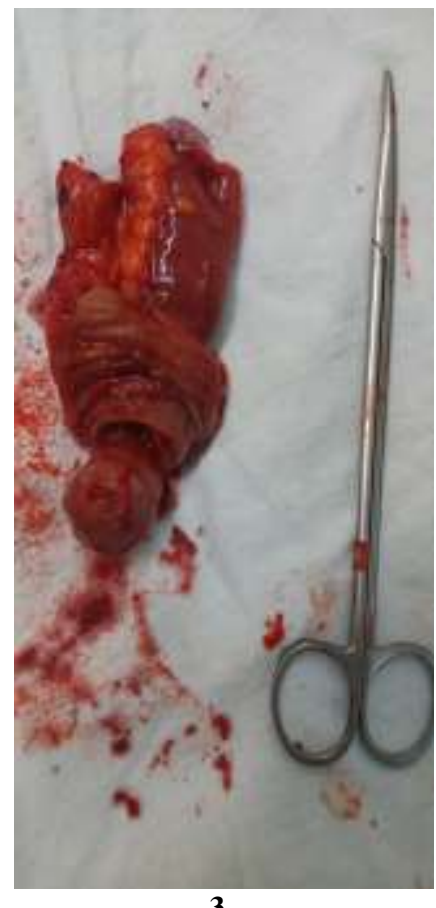

3

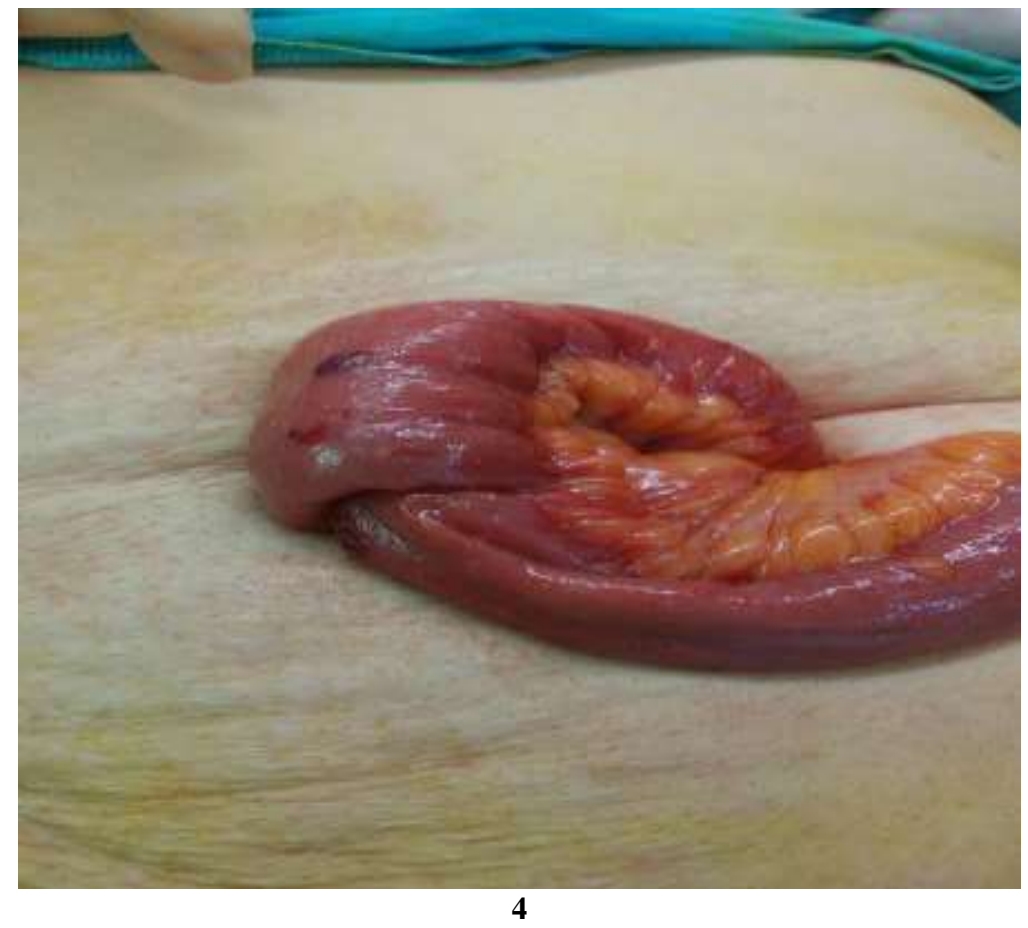

Resim 3-4. Eksplorasyon bulgulart

\section{Tartışma}

İnvajinasyonlar barsağın proksimal segmentinin distaldeki barsağa endoluminal yoldan ilerlemesi sonucu oluşan durumdur. (5) En çok karın ağrısı, akut batın, ileus, dispepsi gibi nonspesifik şikayetlerle belirti vermekle beraber erişkinlerde buna sebep olan etyolojik faktör \% 90 oranında intraoperatif olarak konur. Geriye kalan \% 10'luk dilim idiopatiktir. (2) Kolon invajinasyonları genellikle \% 70 oranında malign sebeplere bağlı iken ince barsak invajinasyonları ise genelde inflamatuar barsak hastalığ postoperatif adezyonlar, meckel divertikülü, intestinal beslenme tüplerine sekonder, lipom, adenom, hamartom, leiomyom gibi benign karakterli lezyonlara sekonderdir. (5) Kolonik, ileokolik ve intestinal olarak 3 grupta sinıflandırılan invajinasyonların \%64'ünün ince barsak, \%36'sının kolonik kaynaklı olduğu Begos ve arkadaşları tarafindan çalışmalırında raporlanmıştır. (2)

Tanısında altın standart olarak bilgisayarlı tomografi kullanılan invajinasyonların preoperatif tanı konma olasılığ olarak gösterilmektedir. (6) Batın tomografisinde ödemli barsak duvarı ve mezenteri, hedef işareti ve 'sosis görünümü' tanı koydurucudur. (5) Erişkin hasta grubunda görülen invajinasyonun temel tedavisi cerrahidir. Perforasyon riski, olası tümör hücrelerinin intraluminal ekimi, tümör hücrelerinin venöz embolizasyonuna neden olması ve deinvajine edilmiş barsak duvarında anastomoz kaçak oranının artması gibi sebeplerle deinvajinasyon önerilmemektedir. (2) Biz de hastamızda malign tümör olasılığı ve anastomoz kaçağı sebeplerinden dolayı segmenter rezeksiyon ve ucuca anastomoz yöntemini uyguladı.

\section{Sonuç}

Erişkin invajinasyonları nadir görülmekle beraber nonspesifik semptomları nedeniyle tanıda gözden kaçabilmektedir. Karın ağrısı, ileus, akut batın gibi semptomlarla başvuran hastalarda invajinasyonlar akilda tutulmalı ve tedavi olarak cerrahi ön planda tutulmalıdır. 


\section{KAYNAKLAR}

1. Andriessen, M. J., Govaert, M. J., \& De Waard, J. W. (2008). Jejunojejunal intussusception by a known jejunal adenocarcinoma. Can J Surg, 51(4), 83-84

2. Begos, D. G., Sandor, A., \& Modlin, I. M. (1997). The diagnosis and management of adult intussusception. The American Journal of Surgery, 173(2), 88-94.

3. Akcay, M. N., Polat, M., Cadirci, M., \& Gencer, B. (1994). Tumor-induced ileo-ileal invagination in adults. The American surgeon, 60(12), 980.
4. Balamoun H, Doughan S. (2011). Ileal lipoma- a rare cause of ileocolic intussusception in adults: Case report and literatüre review. World $J$ Gastrointest Surg, 3:13-5.

5. Azar T, Berger DI. (1997). Adult intussusception. Am Surg. 226(2):134-8.

6. Erkan, N., Hacıyanlı, M., Yıldırım, M., Sayhan, H., Vardar, E., \& Polat, A. F. (2005). Intussusception in adults: an unusual and challenging condition for surgeons. International journal of colorectal disease, 20(5), 452-456. 